\title{
ECCRINE POROCARCINOMA (MALIGNANT ECCRINE POROMA): A SERIES OF EIGHT CHALLENGING CASES
}

doi: $10.1590 / \mathbf{S 1 8 0 7 - 5 9 3 2 2 0 1 0 0 0 0 7 0 0 0 1 4}$

Murilo de Almeida Luz, ${ }^{\mathrm{I}}$ Daniel Cury Ogata, ${ }^{\mathrm{II}}$ Marcos Flávio Gomes Montenegro, ${ }^{\mathrm{II}}$ Luciano José Biasi, ${ }^{\mathrm{II}}$ Leandro Carvalho Ribeiro $^{\text {III }}$

\section{INTRODUCTION}

Eccrine porocarcinoma (EP), a particular malignant sweat gland tumor, represents only $0.005 \%$ of epithelial cutaneous neoplasms. The first reported case was attributed to Pinkus and Mehregan, ${ }^{1}$ and since then, only a few subsequent studies have been presented. Among these reported series, the majority describe aggressive tumor behavior. ${ }^{2-5}$

In this study, we present the features and outcomes of eight fully documented cases (one of the 10 largest singlecenter studies ever published). Although we have previously published a detailed case showing bone invasion and lymph node metastasis, ${ }^{6}$ the current study focuses on the complexities of diagnosis and the overall clinical features that render this ailment difficult to accurately diagnose.

\section{PATIENTS AND METHODS}

Between 1990 and 2005, three surgeons at a single center evaluated and treated eight patients with confirmed EP. The study was approved by the Institutional Ethics Board Committee (number 1519/07). Relevant clinical data were assessed. The TNM classification system for cutaneous carcinomas was applied in each case. A surgical pathologist with expertise in cutaneous malignancies reviewed all of the hematoxylin and eosin (H\&E)-stained slides.

\footnotetext{
${ }^{\text {I }}$ Department of Surgical Oncology, Hospital Erasto Gaertner, Liga Paranaense de Combate ao Câncer - Curitiba/PR, Brazil.

II Department of Pathology Oncology, Hospital Erasto Gaertner, Liga Paranaense de Combate ao Câncer - Curitiba/PR, Brazil.

III Department of Skin Cancer and Melanoma, Hospital Erasto Gaertner, Liga Paranaense de Combate ao Câncer - Curitiba/PR, Brazil.

Email: contato@erastogaertner.com.br

Tel.: $55413361-5000$
}

The diagnosis was established based on the presence of malignant cell clusters that showed an invasive architectural pattern, ductal and eccrine differentiation and cytological pleomorphisms (Figure 1). The ductal differentiation varied from small intracytoplasmic lumens to mature well-established ducts that were lined with a thin eosinophilic layer. No tumor displayed granular cells or decapitated lumens, thus ruling out the possibility of apocrine differentiation. The criteria used to define invasion included tumor desmoplasia and/or the presence of irregular dermis-infiltrating cell clusters. Other observed features included basaloid and clear-cell patterns as well as squamous differentiation.

The parameters evaluated concerning prognostic analysis were the following: lymphovascular invasion, perineural invasion, necrosis and the mitotic index. The mitotic index was analyzed qualitatively, and the cutoff for high or low index was 14 mitotic cells per high-power field (HPF). Vertical growth was assessed from the granular layer to the deepest site of invasion, as noted in the Breslow classification. Any tumor presenting vertical growth greater than $7 \mathrm{~mm}$ was considered thick.

\section{RESULTS}

The mean age was 67 years old. A single primary lesion was present in each case. All patients were Caucasian. Three cases displayed previous contact with agrotoxic agents, while two others admitted to lifelong sunlight exposure without adequate protection. After the initial biopsies (performed in primary care clinics and analyzed by nonexpert diagnostic histopathologists), half of the patients had an inaccurate or incomplete diagnosis, as presented in table 1 . The mean time until definitive treatment by a cancer center was 36 months, ranging from 7 months to 120 

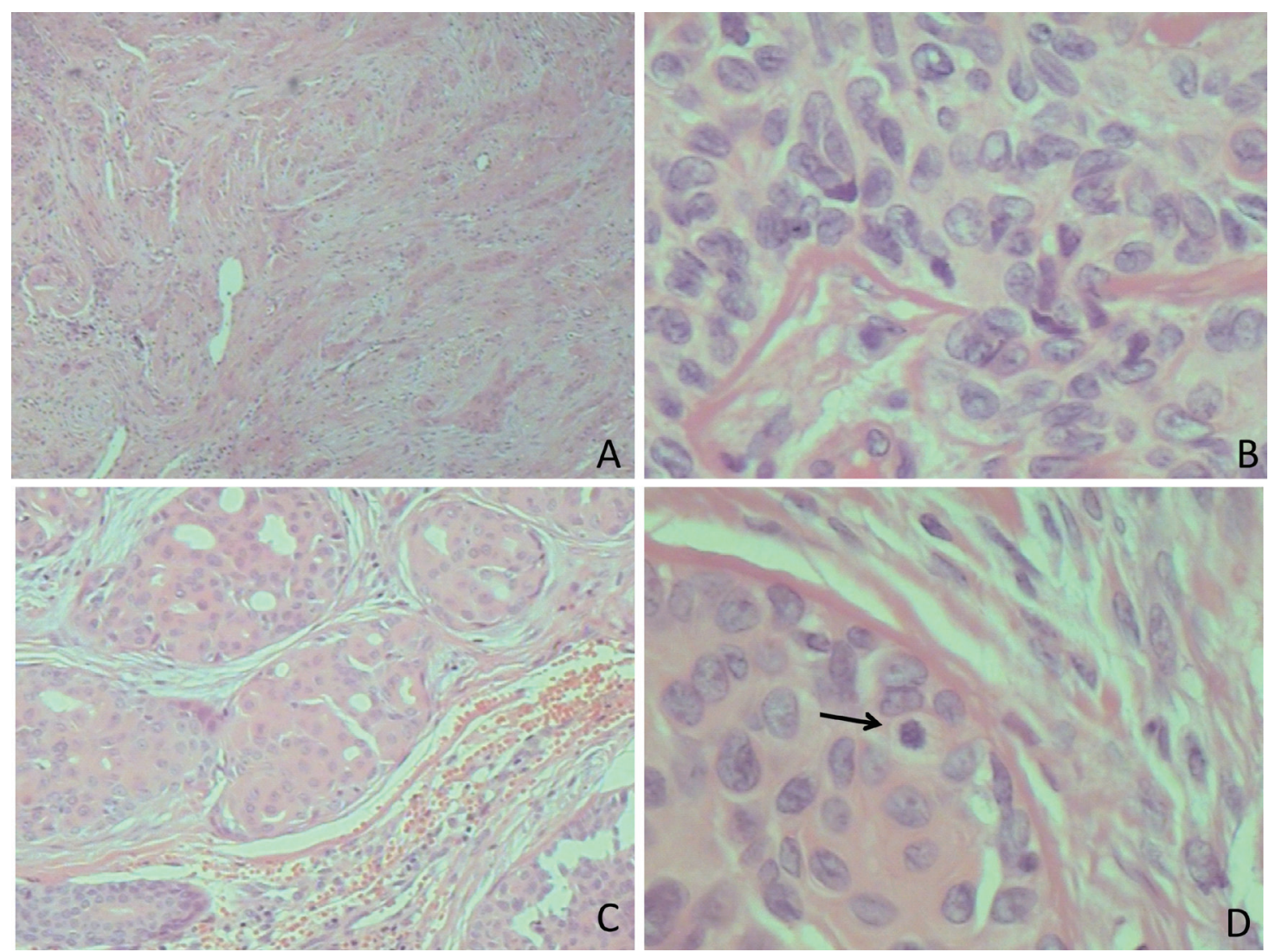

Figure 1 - Eccrine Porocarcinoma - Histology. A. diffuse infiltrative pattern, B. atypical elongated cells and central groove, C. duct formation, D. mitotic figure (arrow)

Table 1 - Pathological report from the initial biopsy for eight cases with an eventual definitive eccrine porocarcinoma diagnosis.

\begin{tabular}{lll}
\hline Patient & Primary Lesion Size $(\mathbf{m m})$ & Diagnosis after Initial Biopsy \\
\hline$\# 1$ & 65 & Excisional biopsy as initial treatment \\
$\# 2$ & 50 & Ulcerated basal cell carcinoma \\
$\# 3$ & 35 & Ulcerated epithelial neoplasm suggestive of porocarcinoma \\
$\# 4$ & 50 & Round cell undifferentiated neoplasm \\
$\# 5$ & 20 & Clear cytoplasm cell carcinoma (suggestive of porocarcinoma) \\
$\# 6$ & 10 & Adnexal skin carcinoma (suggestive of porocarcinoma) \\
$\# 7$ & 100 & Malignant eccrine poroma \\
$\# 8$ & 60 & Squamous cell carcinoma - invasive clear-cell variant \\
\hline
\end{tabular}

months. The mean size of the primary lesion was $48 \mathrm{~mm}$, ranging from $10 \mathrm{~mm}$ to $100 \mathrm{~mm}$. Five patients $(62.5 \%)$ had infected lesions at the initial examination. The clinical and pathological characteristics upon admission are shown in table 2.

None of the tumors were classified as pure "in situ" neoplasia. Only a single case contained all the morphological criteria within the incisional biopsy. Three cases reported an initial suspicion of EP; however, the absence of ductal differentiation prevented a definitive diagnostic conclusion at that time.
Four cases had inaccurate diagnosis at first biopsy. A basaloid cell pattern was present in the specimen analysis of one case, and the absence of ductal differentiation led to the incorrect diagnosis of basal cell carcinoma. Another tumor showed extensive clear-cell components, leading the pathologist to overlook the ductal differentiation and report the final diagnosis as squamous cell carcinoma of the clear-cell subtype. Those two cases were clearly defined as EP after surgical resection because sufficient material for the proper analysis of ductal differentiation was obtained. A third case yielded only a small amount of tissue, and the 
Table 2 - Clinical patterns from eight patients with a definitive eccrine porocarcinoma diagnosis.

\begin{tabular}{|c|c|c|c|c|c|c|c|c|c|c|c|c|}
\hline Case & Age & Sex & Site & $\begin{array}{l}\text { Tumor } \\
\text { Thickness } \\
(\mathrm{mm})\end{array}$ & $\begin{array}{c}\text { Mitotic } \\
\text { Index } \\
\text { (per HPF) }\end{array}$ & Necrosis & LVI & PNI & LN & Stage* & Status & OS \\
\hline$\# 1$ & 61 & $\mathrm{~F}$ & Scalp & $<7$ & $>14$ & Yes & Yes & Yes & Yes & III & DOD & 36 \\
\hline$\# 2$ & 64 & $\mathrm{~F}$ & Shoulder & $>7$ & $<14$ & Yes & Yes & No & No & II & NED & 180 \\
\hline$\# 3$ & 50 & F & Leg & $>7$ & $<14$ & Yes & Yes & Yes & Yes & III & NED & 360 \\
\hline \#4 & 64 & F & Leg & $>7$ & $<14$ & Yes & No & Yes & No & II & NED & 230 \\
\hline$\# 5$ & 73 & M & Tight & $<7$ & $<14$ & No & No & No & No & I & NED & 18 \\
\hline \#6 & 55 & M & Forearm & $<7$ & $<14$ & No & No & No & No & I & NED & 36 \\
\hline \#7 & 82 & F & Buttock & $>7$ & $>14$ & Yes & Yes & Yes & Yes & III & DOD & 6 \\
\hline \#8 & 58 & M & Neck & $>7$ & $>14$ & Yes & Yes & No & Yes & III & AWD & 18 \\
\hline
\end{tabular}

LVI: lymphovascular invasion, PNI: perineural invasion, OS: overall survival (in months), LN: lymph node metastasis, *TNM (section: cutaneous carcinoma), NED: no evidence of disease, DOD: died of disease, DOI: died of intercurrent disease, AWD: alive with recurrent disease.

analysis was thus impaired. As a consequence, an incorrect diagnosis of "undifferentiated" small round-cell neoplasm was reported. Definitive surgery gave better-quality tissue for an accurate analysis, and the final diagnosis was EP. The fourth case had inconclusive initial analysis and we thus performed a complete excisional biopsy which rendered the diagnosis of EP. The histopathological prognostic factors are shown in table 2.

The standard treatment performed was wide resection. There is no clear recommendation in the literature regarding surgical margins for EP tumors. As such, we used our routine protocol for non-melanoma skin cancer, applying clear margins of at least $10 \mathrm{~mm}$. In three patients, the resection was followed by a lymphadenectomy (inguinal or cervical). A single patient received palliative chemotherapy after unresectable local recurrence, while another two patients underwent adjuvant radiation therapy, one for close resection margins and the other because of lymph node macrometastasis.

The mean follow-up time was 74 months. Of the eight cases, six patients remain alive: Five patients have no evidence of disease, and one patient has confirmed regional recurrence. The two other patients died of EP-related complications. One of these two patients had an extensive recurrence, and his age did not allow further treatment. The second patient died following a second recurrence, three years after the initial diagnosis.

\section{DISCUSSION}

We have presented the approach and outcomes of eight EP cases. The study stresses the major problems with this particular type of tumor and the delay in definitive treatment attributed to the tumor's indolent behavior or misleading clinical diagnosis upon inexpert medical evaluation. Pathologically speaking, this neoplasia demonstrated an aggressive behavior compared with common nonmelanoma skin cancer.

EP has a propensity to arise on the lower limbs (44\%), trunk (24\%) or head and neck region (24\%)..$^{3-4,7-8}$ However, rare cases of penile involvement have been reported. ${ }^{8}$ Morphologically, tumors vary greatly in size, from less than $1 \mathrm{~cm}$ up to $10 \mathrm{~cm}$. A long period of clinical history is often encountered (up to 50 years) because some of these tumors could have arisen from a preexisting benign eccrine poroma. Regional lymph node metastases are found in about $20 \%$ of patients, and distant metastases arise in about $10 \%$ of patients. ${ }^{4-5,8}$

The disease may appear nodular, infiltrative, ulcerated or polypoid. Multinodularity, ulceration and rapid growth may be associated with either local recurrence or metastasis. ${ }^{2}$ The clinical differential diagnoses of these lesions include seborrheic keratosis, pyogenic granuloma, amelanotic melanoma, squamous cell carcinoma, basal cell carcinoma, verruca vulgaris, and metastatic adenocarcinoma. ${ }^{2,3}$

As we have shown, the initial pathology report can easily lead to a misdiagnosis. Even defined EPs may show some kind of basal or squamous differentiation. ${ }^{9}$ The tumor is typically formed of cohesive basaloid epithelial cells. This morphological appearance can include squamous cells, clear cells, spindle cell differentiation, mucous cell metaplasia, a Paget phenomenon and colonization by melanocytes. ${ }^{6-7,10}$ Clear-cell changes are frequently observed and are attributed to moderate amounts of glycogen, as detected by periodic acid-Schiff (PAS) and PAS after digestion with diastase. ${ }^{5,8}$ Immunohistochemical techniques are not strictly necessary; 
however, they may be used to confirm the diagnosis. The cells that line the neoplastic ducts and clefts are positive for carcinoembrionic antigen and negative for $\mathrm{S} 100$ protein (myoepithelial cells from the glandular portion are positive for $\mathrm{S} 100$ protein). ${ }^{3-4}$ These findings confirm a primitive eccrine ductal differentiation.

Clinicians will often render a worse prognosis because of a mitotic index of more than 14 mitotic cells per HPF, lymphovascular invasion and a tumor depth exceeding $7 \mathrm{~mm} .{ }^{11-13}$ Although the gross size of a tumor has no significant relationship to prognosis, a tumor depth $>7 \mathrm{~mm}$ predicted both death and lymph node involvement in this study. Finally, an infiltrative tumor margin had a dramatic influence on local recurrence. ${ }^{2-3}$ In a great majority of cases, a well-handled specimen and an expert pathology and oncology department can help the attending surgeon achieve a definitive diagnosis.

Cutaneous EP is rarely diagnosed preoperatively; thus, surgical management is usually not initially planned. Although wide local excision of any cutaneous tumor is recommended, the results from historical series suggest that EPs with an infiltrative pattern may benefit from further surgery if doubts exists regarding the completeness of the excision. ${ }^{2-4,8}$ Because of the high rate of local recurrence, a wide excision of the primary tumor, with histologically clear margins, is mandatory. ${ }^{7}$ Proper surgical resection leads to curative outcomes in $70 \%$ to $80 \%$ of cases. . $^{3-5,14-15}$ However, micrographic surgery has been attempted to reduce the morbidity and local recurrence with good initial results. ${ }^{14}$ There are no strong data available favoring adjuvant therapy in this setting. Anecdotal reports show some benefits when utilizing radiation or chemotherapy. ${ }^{16-17}$ Barzi et al. proposed a new protocol that utilizes isotretinoin and interferon alpha to treat metastatic disease, yielding hopeful results. ${ }^{12}$ Nevertheless, there are few studies addressing the application of chemotherapy to EP without metastasis. ${ }^{17}$

EP is still very challenging for surgeons and medical/ radiation oncologists. Because of its rarity, morphologic peculiarity and ambiguous similarity to other carcinomas, guidelines and strong recommendations are not widely available. However, professionals involved in skin cancer treatment should be aware of this disease. Because the cases are rare and each center has only a few of them, publications from cooperative multicentric groups are needed. These groups are able to pool several patients getting a larger number of cases and increasing the data relevance in order to facilitate clinical decisions when dealing with such an intriguing neoplasia.

\section{REFERENCES}

1. Pinkus H, Mehregan AH. Epidermotropic eccrine carcinoma. Arch Dermatol. 1963;88:597-606.

2. Robson A, Greene J, Ansari N, Kim B, Seed PT, McKee PH, et al. Eccrine Porocarcinoma (Malignant Eccrine Poroma) A Clinicopathologic Study of 69 Cases. Am J Surg Pathol. 2001;25:710-20.

3. Shiohara J, Koga H, Uhara H, Takata M, Saida T. Eccrine porocarcinoma: clinical and pathological studies of 12 cases. J Dermatol. 2007;181:51622.

4. Orella JAL, Penalba AV, San Juan CC, Nadal RV, Morrondo JC, Alvarez TT. Eccrine Porocarcinoma: Report of nine cases. Dermat Surg. 1997:23:925-28.

5. Shaw M, McKee PH, Lowe D, Black MM. Malignant eccrine poroma: a study of twenty-seven cases. Br J Dermatol. 1982;107:675-80.

6. Ribeiro LC, Luz MA, Montenegro MFG, Biasi LJ, Ogata DC. Eccrine Porocarcinoma (Malignant Eccrine Poroma) with Bone Invasion and Lymph Node Metastases. App Cancer Res. 2008;28:165-67.

7. Snow SN, Reizner GT. Eccrine porocarcinoma of the face. J Am Acad Dermatol. 1992;27:306-11.

8. Grayson W, Loubser JS. Eccrine Porocarcinoma of the Penis J Urol. 2003;169: 611-2.

9. Klenzner T, Arapakis I, Kayser G, Boedeker CC. Eccrine porocarcinoma of the ear mimicking basaloid squamous cell carcinoma. Otolaryngol Head Neck Surg. 2006;135:158-60.
10. Brown Jr. CW, Dy LC. Eccrine porocarcinoma. Y Derm Ther. 2008;21:433-8.

11. Mahomed F, Blok J, Grayson W. The squamous variant of eccrine porocarcinoma: a clinicopathological study of 21 cases. J Clin Pathol. 2008;61:361-5.

12. Barzi AS, Ruggeri S, Recchia F, Bertoldi I. Malignant metastatic eccrine poroma. Dermatol Surg. 1997;23:267-72.

13. Chang NC, Tsai KB. Eccrine Porocarcinoma of the Auricle: A Case Report. Kaohsiung J Med Sci. 2009;25:401-4.

14. Poiares Baptista A, Tellechea O, Reis JP, Cunha MF, Figueiredo P. Eccrine porocarcinoma: A review of 24 cases. Ann Dermatol Venereol. 1993;120:107-15.

15. Wittenberg GP, Robertson DB, Solomon AR, Washington CV. Eccrine Porocarcinoma treated with Mohs Micrographic Surgery: A Report of Five Cases. Dermatol Surg. 1999;25:911-3.

16. Gutermuth J, Audring H, Voit C, Trefzer U, Haas N. Antitumour activity of paclitaxel and interferon-alpha in a case of metastatic eccrine porocarcinoma. J Eur Acad Dermatol Venereol. 2004;18:477-9.

17. de Bree E, Volalakis E, Tsetis D, Varthalitis Y, Panagiotidis J, Romanos J et al. Treatment of advanced malignant eccrine poroma with locoregional chemotherapy. Br J Derm. 2005;152:1051-5. 